\title{
Reduction of Energetic Demands through Modification of Body Size and Routine Metabolic Rates in Extremophile Fish
}

\author{
Courtney N. Passow ${ }^{1, *}$ \\ Ryan Greenway ${ }^{1, \dagger}$ \\ Lenin Arias-Rodriguez ${ }^{2}$ \\ Punidan D. Jeyasingh ${ }^{1}$ \\ Michael Tobler ${ }^{1, \dagger}$ \\ ${ }^{1}$ Department of Zoology, Oklahoma State University, 501 \\ Life Sciences West, Stillwater, Oklahoma 74078; ${ }^{2}$ División \\ Académica de Ciencias Biológicas, Universidad Juárez \\ Autónoma de Tabasco, Villahermosa, Tabasco, Mexico
}

Accepted 2/13/2015; Electronically Published 3/23/2015

Online enhancements: appendix figures and tables.

\begin{abstract}
Variation in energy availability or maintenance costs in extreme environments can exert selection for efficient energy use, and reductions in organismal energy demand can be achieved in two ways: reducing body mass or metabolic suppression. Whether long-term exposure to extreme environmental conditions drives adaptive shifts in body mass or metabolic rates remains an open question. We studied body size variation and variation in routine metabolic rates in locally adapted populations of extremophile fish (Poecilia mexicana) living in toxic, hydrogen sulfide-rich springs and caves. We quantified size distributions and routine metabolic rates in wild-caught individuals from four habitat types. Compared with ancestral populations in nonsulfidic surface habitats, extremophile populations were characterized by significant reductions in body size. Despite elevated metabolic rates in cave fish, the body size reduction precipitated in significantly reduced energy demands in all extremophile populations. Laboratory experiments on common garden-raised fish indicated that elevated routine metabolic rates in cave fish likely have a genetic basis. The results of this study indicate that adaptation to extreme environments directly impacts energy metabolism, with fish living in cave and sulfide spring environments expending less energy overall during routine metabolism.
\end{abstract}

${ }^{*}$ Corresponding author. Present address: Division of Biology, Kansas State University, 116 Ackert Hall, Manhattan, Kansas 66506; e-mail: cnpassow@ksu.edu. $\dagger$ Present address: Division of Biology, Kansas State University, 116 Ackert Hall, Manhattan, Kansas 66506.

Physiological and Biochemical Zoology 88(4):371-383. 2015. (C) 2015 by The University of Chicago. All rights reserved. 1522-2152/2015/8804-4021\$15.00. DOI: $10.1086 / 681053$
Keywords: adaptation, cave environments, energy consumption, extreme environments, hydrogen sulfide springs, Poecilia mexicana, resource availability.

\section{Introduction}

Animals require energy for maintenance, growth, and reproduction, and since individuals' energy expenditure may be greater or less than the environmental energy availability, they can modulate a variety of physiological processes to balance energy supply and expenditure (Cho et al. 1982). Metabolic rate is a physiological measure of the rate at which organisms burn calories from assimilated food resources to produce energy for organismal functioning, and understanding metabolic rate variation is critical for investigating ecological processes at multiple levels of organization (Brown et al. 2004; Sibly et al. 2012). The majority of metabolic rate variation in animals coincides with variation in body mass and temperature (Peters 1983; Gillooly et al. 2001; Brown et al. 2004; Clarke and Fraser 2004; Cano and Nicieza 2006). Nonetheless, massand temperature-adjusted metabolic rates can vary substantially even among closely related taxa (McNab 1986; Clarke and Johnston 1999; Nagy et al. 1999; Lovegrove 2000; Schaefer and Walters 2010). Elucidating the selective forces that shape such residual metabolic rate variation in allometric plots and underlie macroevolutionary patterns in the diversification of metabolic rates is a critical challenge in physiology (Garland and Carter 1994; Feder et al. 2000).

Resource availability is a strong source of selection driving adaptive modification of metabolic rates within and among closely related species (Mueller and Diamond 2001; McCue 2010; Moiroux et al. 2012). From an energetic point of view, fitness can be described as the conversion rate of energy into offspring (Brown et al. 1993), which ultimately is limited first by the rate at which organisms can acquire energy from the environment and then by the rate at which they can allocate energy to reproduction (as opposed to maintenance or growth). Consequently, reductions in environmental resource availability or increases in maintenance or growth costs are predicted to constrain the amount of energy for reproduction and exert selection for a reduced overall energy demand that allows for maximizing relative energy allocation to the production of offspring. Organisms can reduce their overall energy demand in two fundamental ways. First, they can reduce their body size by reducing energy allocation to growth, which simultaneously reduces total energy expenditure for maintenance 
(Blanckenhorn 2000; Wikelski and Romero 2003; Pafilis et al. 2009; McNab 2010). Second, organisms can reduce metabolic rate independently of body size, which changes the allometric relationship between metabolism and body size (Guppy and Withers 1999; Wang et al. 2006; Burton et al. 2011). It is important to note that these mechanisms are not mutually exclusive but may work in synchrony, such that focusing merely on body size or metabolic rates alone can lead to erroneous conclusions (McNab 1999, 2002; Van Voorhies et al. 2004; McCue 2010).

Systems in which closely related populations occur in habitats with starkly different environmental conditions provide an excellent opportunity to study evolutionary change in organismal energy demand. This is especially true for species that have invaded extreme environments, and comparisons between populations in localized extreme environments and adjacent "benign" habitats allow for a powerful approach to examine the effects of stressors on organismal physiology as well as the evolutionary trajectories of populations. Exposure to physicochemical stressors profoundly affects energy budgets of organisms because the maintenance of homeostasis precipitates in considerable energetic costs through investments in physiological, morphological, or behavioral coping mechanisms (Calow 1989; Sibly and Calow 1989; Parsons 1996). As such, continuous exposure to environmental stressors should select for increased metabolic rates (e.g., Knoblauch et al. 1999). However, the evolution of increased metabolic rates in extreme environments is typically constrained by a reduced supply of resources required for metabolic expenditure (Waterman 1999, 2001). While many studies have investigated immediate metabolic costs of exposure to physicochemical stressors and energy limitation (e.g., Haney and Nordlie 1997; Penttinen and Kukkonen 1998; Rose et al. 2006; Wang et al. 2006; McKenzie et al. 2007; McCue 2010), it remains unclear how metabolic rates and metabolic rate plasticity evolve when populations adapt to diverse environmental stressors. Here, we explicitly tested for differences in body size and routine metabolic rate in the context of resource limitation in extremophile fish. Such information will be important for a more general understanding of metabolic rate evolution (Naya et al. 2013).

Poecilia mexicana is a livebearing fish that has repeatedly colonized extreme environments characterized by the presence of naturally occurring toxic hydrogen sulfide $\left(\mathrm{H}_{2} \mathrm{~S}\right)$ and the absence of light in caves (Tobler and Plath 2011; Tobler et al. 2011). In Mexico's Cueva del Azufre system, both environmental factors occur in a natural, factorial design forming four distinct habitat types: nonsulfidic surface streams, sulfidic surface streams, a nonsulfidic cave, and a sulfidic cave (Tobler et al. 2008a; Plath and Tobler 2010). Populations from different habitat types are characterized by adaptive trait divergence (Tobler et al. 2008a; Tobler and Plath 2011) and are reproductively isolated with low rates of gene flow among populations living under different environmental conditions (Plath et al. 2007a, 2010). Reproductive isolation is mediated at least in part by natural selection against nonadapted, migrant in- dividuals and by sexual selection through ecotype-assortative mating (Tobler 2009; Tobler et al. 2009b; Riesch et al. 2011a).

The strikingly different environmental conditions in this system are expected to profoundly affect organismal energy budgets. Caves have been widely considered as energy limited because of a lack of photosynthetic primary production (Poulson and White 1969; Langecker 2000), and some cave organisms accordingly have evolved lower metabolic rates (e.g., Hüppop 1985, 1986; Hervant et al. 2000; Poulson 2001; Wilhelm et al. 2006). Similarly, exposure to $\mathrm{H}_{2} \mathrm{~S}$ has been shown to constrain energy acquisition in P. mexicana (Tobler et al. $2009 a) . \mathrm{H}_{2} \mathrm{~S}$ causes and aggravates hypoxia in natural environments (Bagarinao 1992), driving exposed fish to trade off time between benthic foraging and aquatic surface respiration, which directly mediates survival in the toxic and hypoxic environment (Plath et al. 2007b; Tobler et al. 2009a). In addition, exposure to perpetually sulfidic environments requires active detoxification for survival. Sulfide spring fish exhibit a heritable and constitutive increase in $\mathrm{H}_{2} \mathrm{~S}$ detoxification ability through upregulation of the sulfide:quinone oxidoreductase pathway (Tobler et al. 2014), a process that is energetically costly (Ip et al. 2004; Hildebrandt and Grieshaber 2008). Accordingly, some organisms adapted to sulfidic environments have been documented to increase energy consumption in the presence of $\mathrm{H}_{2} \mathrm{~S}$ (Gorodezky and Childress 1994; Schneider 1996). Clearly, exposure to extreme environmental conditions impacts organismal energy budgets through reduced energy availability, reduced ability for energy acquisition, and/or increased organismal maintenance costs, which is reflected in P. mexicana from both sulfidic and cave environments consistently having a lower body condition than fish from nonsulfidic surface habitats (assessed through abdominal distension [Plath et al. 2005], body fat content [Tobler 2008], and mass-length relationships [Tobler et al. 2006]). Consequently, adaptation to these environments should be linked to energy metabolism, and we hypothesized that extremophile populations should be selected for reductions in overall energy demand. To test this overarching hypothesis, we addressed the following objectives: (1) we quantified size distributions of fish in different habitat types to test whether adaptation to extreme environments was associated with body size reduction; (2) we quantified routine metabolic rates in wild-caught individuals to test whether adaptation to extreme environments was associated with metabolic rate suppression; and (3) we tested for a genetic basis of variation in metabolic rates and metabolic rate plasticity in response to energy availability by quantifying routine metabolic rates in common garden-raised individuals subjected to different food treatments.

\section{Material and Methods}

\section{Study Sites}

To disentangle potential effects of the presence of hydrogen sulfide and permanent darkness in caves on organismal energy demands, we focused on a set of habitats in the Cueva del Azufre system, where these environmental factors occur in a 
natural, factorial design: (1) a nonsulfidic surface habitat (Arroyo Bonita), (2) a sulfidic surface habitat (El Azufre), (3) a nonsulfidic cave (Cueva Luna Azufre), and (4) a sulfidic cave (Cueva del Azufre, chamber V). All sites were located within $4 \mathrm{~km}$ of each other and were situated near the village of Tapijulapa in the Mexican state of Tabasco (Tobler et al. 2008a). The sulfidic cave is segregated into different chambers with varying exposure of light and high densities of Poecilia mexicana (Gordon and Rosen 1962; Parzefall 2001), while the nonsulfidic cave is considerably smaller than the sulfur cave, completely dark, and maintains only a small $P$. mexicana population (Tobler et al. 2008b). Fish from the sulfidic surface habitat were collected in the El Azufre, a stream that drains the Cueva del Azufre and eventually joins the Rio Oxolotan. The nonsulfidic habitat (Arroyo Bonita) is also a tributary of the Rio Oxolotan and is similar in size and structure to that of the El Azufre (Tobler et al. 2008a). All procedures conducted for this study were approved by the Institutional Animal Care and Use Committee at Oklahoma State University (Animal Care and Use Protocol AS10-15).

\section{Size Distribution in Natural Populations}

To compare size distributions in the four habitat types, we assembled data from previous studies (Tobler 2008; Tobler et al. 2006, 2008a, 2008b, 2008c) as well as several unpublished projects. In all cases, fish were collected using seines ( $4 \mathrm{~m}$ long, $4 \mathrm{~mm}$ mesh width), sexed, and weighed (blotted wet weight to the closest $0.01 \mathrm{~g}$ ). Mass-based size distributions were then analyzed using ANOVA with body mass as a dependent variable. We included sex, presence or absence of $\mathrm{H}_{2} \mathrm{~S}$ (i.e., sulfidic vs. nonsulfidic habitat), and presence or absence of light (i.e., cave vs. surface habitat) as independent variables.

\section{Determining Routine Metabolic Rates in Natural Populations}

For the quantification of metabolic rates in wild-caught fish, specimens were collected in June 2012. On capture, fish were immediately transferred into insulated coolers with aerated water and transported to a nearby field station at the Centro de Investigación e Innovación para la Enseñanza y el Aprendizaje in Teapa, Tabasco. Before metabolic rate trials, fish were allowed to acclimate to laboratory conditions for at least $48 \mathrm{~h}$. During that time, they were kept in 70-L tanks with filtered and aerated water. The temperature was kept between $24^{\circ}$ and $26^{\circ} \mathrm{C}$. All fish were subjected to a $12 \mathrm{~L}: 12 \mathrm{D}$ photoperiod.

We employed a closed-chamber respirometry approach to quantify an individual's routine metabolic rate, which is defined as the oxygen consumption of unconstrained, postabsorptive organisms capable of spontaneous motor activity (Fry 1957; Steffensen 1989). This approach has been widely used to quantify metabolic costs associated with a variety of factors, including exposure to environmental stressors (Haney and Nordlie 1997; Pirozzi and Booth 2009), locomotion (Basolo and Alcaraz 2003; Seibel and Drazen 2007), elaborate morphological structures (Allen and Levinton 2007), mating behaviors (Hoback and Wagner 1997), and gestation (Timmerman and Chapman 2003). The protocol for measurements of oxygen consumption included the following steps for each individual. (1) As detritivores, P. mexicana have a relatively fast gut passage time of $<6 \mathrm{~h}$ (M. Tobler and K. Scharnweber, unpublished data). Hence, fish were not fed $24 \mathrm{~h}$ before trials to ensure that metabolic rate measurements were conducted on postabsorptive individuals (Timmerman and Chapman 2004b; Norin and Malte 2011). (2) Fish were haphazardly chosen from stock tanks and placed into individual respirometry bottles filled three-fourths with water for a 12-h acclimation period under continuous aeration. Bottles had a total volume of $580 \mathrm{~mL}$ and were painted solid black to prevent light penetration. Four bottles were placed together in a black equipment box with a lid to further minimize light exposure and with water to minimize temperature fluctuations in the respirometry bottles. Realized mean temperatures in respirometry bottles ranged from $26.1^{\circ}$ to $27.2^{\circ} \mathrm{C}$ across all trials. (3) After the acclimation period, the respirometry chambers were flushed with fresh, aerated water to remove metabolic waste products (Timmerman and Chapman 2004a) and capped with a fitted lid that allowed for the insertion of an oxygen probe. Once capped, water was added to the chamber using a squirt bottle to remove any excess air, and a YSI ProDO optical dissolved oxygen probe (YSI, Yellow Springs, $\mathrm{OH}$ ) was inserted into each bottle (this probe monitors dissolved oxygen concentration in conjunction with temperature). Plumbers putty was fitted around the oxygen probe to prevent any diffusion of gases. Once all four respirometry bottles were set up, the lid of the water bath was closed, and the probes were set to measure the dissolved oxygen concentration at 10 -s intervals. All experiments were run for at least $6 \mathrm{~h}$ or until the oxygen saturation reached $10 \%$, to prevent mortality. Probes were recalibrated regularly according to the manufacturer's recommendations to maintain accuracy. Note that all metabolic rate trials were conducted in the absence of $\mathrm{H}_{2} \mathrm{~S}$, even for sulfidic populations, because the reactivity of $\mathrm{H}_{2} \mathrm{~S}$ with oxygen in aqueous solution (Chen and Morris 1972) affects estimates of organismal oxygen consumption. (4) After termination of a trial, individuals were weighed (blotted wet weight to the closest $0.01 \mathrm{~g}$ ) and sexed. Descriptive statistics for the body mass of individuals used are given in table 1 .

Raw data obtained from all trials represented measurements of oxygen concentration and temperature through time. For each individual trial, we first removed any outliers that were likely caused by instrumental error ( $<0.1 \%$ of data points). We also removed any data points from the first $60 \mathrm{~min}$ of each trial, as the flushing of the respirometry bottle with fresh water and the installation of the oxygen probe may have caused erratic fish activity (Timmerman and Chapman 2004b). Because fish metabolic rates may be affected by reduced ambient oxygen concentrations (Haney and Nordlie 1997; Ultsch et al. 1978), we included only data points measured at dissolved oxygen saturations $>70 \%$. Metabolic rate $\left(\mathrm{mg} \mathrm{O}_{2} / \mathrm{h}\right)$ was then calculated for each individual as the slope of a regression (multiplied by the volume of water in the respiratory bottle) with 
Table 1: Descriptive statistics for body masses as well as sample sizes of fish used in metabolic rate trials with wild-caught and common garden-raised individuals of Poecilia mexicana

\begin{tabular}{|c|c|c|c|c|c|c|}
\hline & \multirow[b]{2}{*}{ Wild-caught females } & \multirow[b]{2}{*}{ Wild-caught males } & \multicolumn{2}{|c|}{ Laboratory-raised females } & \multicolumn{2}{|c|}{ Laboratory-raised males } \\
\hline & & & High food & Low food & High food & Low food \\
\hline \multicolumn{7}{|c|}{ Nonsulfidic surface: } \\
\hline Mean \pm SD & $1.07 \pm .47$ & $1.07 \pm .80$ & $1.01 \pm .33$ & $1.09 \pm .37$ & $.70 \pm .17$ & $.52 \pm .04$ \\
\hline Range & $.23-1.88$ & $.26-2.32$ & $.39-1.67$ & $.61-1.69$ & $.52-.91$ & $.48-.58$ \\
\hline$N$ & 15 & 5 & 23 & 24 & 6 & 4 \\
\hline \multicolumn{7}{|l|}{ Sulfidic surface: } \\
\hline Mean \pm SD & $1.04 \pm .45$ & $.74 \pm .21$ & $1.17 \pm .53$ & $.49 \pm .10$ & $.54 \pm .09$ & $.48 \pm .08$ \\
\hline Range & $.43-2.04$ & $.51-.98$ & $.56-2.52$ & $.34-.66$ & $.41-.71$ & $.36-.67$ \\
\hline$N$ & 16 & 4 & 11 & 10 & 17 & 19 \\
\hline \multicolumn{7}{|l|}{ Nonsulfidic cave: } \\
\hline Mean \pm SD & $.58 \pm .21$ & $.24 \pm .08$ & $1.08 \pm .27$ & $.94 \pm .35$ & $.53 \pm .11$ & $.54 \pm .14$ \\
\hline Range & $.21-.81$ & $.16-.41$ & $.53-1.88$ & $.73-1.81$ & $.41-.74$ & $.38-.82$ \\
\hline$N$ & 7 & 8 & 21 & 15 & 8 & 13 \\
\hline \multicolumn{7}{|l|}{ Sulfidic cave: } \\
\hline Mean \pm SD & $1.15 \pm .36$ & $.69 \pm .55$ & $1.02 \pm .50$ & $.91 \pm .42$ & $.69 \pm .13$ & $.58 \pm .16$ \\
\hline Range & $.36-1.71$ & $.40-2.00$ & $.55-2.03$ & $.50-1.66$ & $.45-.82$ & $.29-.45$ \\
\hline$N$ & 12 & 7 & 15 & 11 & 12 & 13 \\
\hline
\end{tabular}

Note. All measurements of body mass are provided as mean \pm SD and range (minimum to maximum) in grams; the sample size ( $N$ ) of each experimental group is also provided. Overall sample size was $N=74$ for the field experiment and $N=222$ for the laboratory experiment.

oxygen concentration as a dependent variable and time as an independent variable. For all regressions, $R^{2}$ was $>0.90$.

Routine metabolic rate data were analyzed using ANCOVA. $\log _{10}$-transformed routine metabolic rate was used as a dependent variable. We included sex, presence or absence of $\mathrm{H}_{2} \mathrm{~S}$ in natural populations (i.e., sulfidic vs. nonsulfidic habitat), and presence or absence of light in natural populations (i.e., cave vs. surface habitat) as independent variables. Temperature and mass $\left(\log _{10}\right.$ transformed) were included as covariates in all models. All three-way $(F \leq 1.909, P \geq 0.173)$ and two-way $(F \leq$ 2.780, $P \geq 0.101$ ) interaction terms were not significant and thus excluded from the final model.

\section{Genetic Basis of Variation in Routine Metabolic Rates and Metabolic Rate Plasticity}

Metabolic rate variation in wild-caught fish may merely reflect plastic responses to life under different environmental conditions. Hence, we tested whether differences in routine metabolic rates documented in wild-caught individuals have a genetic basis by using common garden-raised fish from the same populations investigated in the field. In addition, we used experimental manipulations of energy availability to test for population differences in metabolic rate plasticity in response to energy availability.

Common garden-raised fish came from stocks at the University of Oklahoma and Oklahoma State University. All animals used in the laboratory portion of this study were born and raised in captivity, and fish were maintained under nonsulfidic conditions with a $12 \mathrm{~L}: 12 \mathrm{D}$ photoperiod. Individuals for the metabolic rate experiment were haphazardly chosen from stock tanks. Each fish was sexed and weighed (blotted wet weight to the closest $0.01 \mathrm{~g}$; table 1 ), and five fish from the same population were introduced into a 40 - $\mathrm{L}$ tank with filtered and aerated water (these are low stocking densities compared with regular stock tanks and were used to minimize competition between individuals). Tanks were assigned to different food treatments in a balanced fashion (i.e., neighboring tanks alternated in population and food treatment assignment) for a total of eight tanks per treatment. During the experiment, all fish were fed with Earthworm Fish Flakes (American Brine Shrimp Company, Ogden, UT). To standardize resource availability, we calculated the total fish mass for each tank. For the high food treatment, we calculated the amount of food $\left(\mathrm{HF}\right.$, in grams) as $\mathrm{HF}=0.0125 \times(\text { total fish mass })^{0.65}$. Low food treatment groups received half the amount of food provided to high food treatment groups. Fish were fed the calculated amount of food twice a day from Monday through Friday and once a day during the weekend. All fish were kept on their respective food treatment for at least $21 \mathrm{~d}$ before testing. During this time, the temperature was kept constant at $25^{\circ} \mathrm{C}$. Upon completion of a trial, fish were returned to regular stock tanks.

In general, the experimental protocol for metabolic rate measurements was identical for the wild-caught and common garden-raised fish. There were only two critical differences. First, instead of handheld oxygen probes, the oxygen consumption measurements were conducted using a Loligo Systems (Tjele, Denmark) four-channel respirometry system with fiber optic probes. Oxygen concentrations and temperature were measured every second. Second, the temperature in the water bath was controlled using an Ebo-Jäger 75-W aquarium 
heater (EHEIM, Deizisau, Germany) in conjunction with a Mighty Pro chiller (AquaEuroUSA, Gardena, CA). Fish were tested at $20^{\circ}, 25^{\circ}$, or $30^{\circ} \mathrm{C}$, to test for potential population differences in the temperature dependence of metabolic rates. The four habitat types investigated here vary in both mean temperatures and temperature variability (with extreme environments typically exhibiting higher averages and lower variability), and the chosen temperatures reflect the range that $P$. mexicana typically encounter in natural habitats (Tobler et al. 2006, 2008a).

Statistical analyses were conducted as outlined above for the wild-caught fish, except that the ANCOVA model for the laboratory-reared fish also included food treatment (high vs. low) as an independent variable. Three-way interactions ( $F \leq$ 2.684, $P \geq 0.103)$ as well as interaction terms including temperature $(F \leq 0.379, P \geq 0.539)$ were not significant and hence excluded from the final model.

\section{Results}

\section{Size Distributions}

Overall, we assembled mass data for 1,454 individuals. ANOVA indicated that males exhibited a significantly smaller body size than females in all populations (table 2, pt. A), which is likely related to the fact that male poeciliids, unlike females, have determinate growth (Constantz 1989; Reznick and Miles 1989). More importantly, we detected a significant cave $\times$ sulfide interaction (as well as significant cave and sulfide main effects), indicating significant body size differences among populations residing in different habitat types. Individuals from the ancestral population in the nonsulfidic surface habitat were by far the largest, with a mass of $2.01 \pm 1.20 \mathrm{~g}$ (mean \pm $\mathrm{SD}$; fig. 1A). In contrast, all individuals from extreme environments exhibited a reduction in overall body mass, with individuals $>3.00$ g being exceedingly rare (fig. $1 B-1 D$ ). Among

Table 2: Results of ANOVA and ANCOVA explaining variation in body size and metabolic rates

\begin{tabular}{|c|c|c|c|c|}
\hline Variable & df & $F$ & $P$ & $\eta_{\mathrm{p}}^{2}$ \\
\hline \multicolumn{5}{|c|}{ A. Body mass ( $\log _{10}$ transformed): } \\
\hline Sex & 1 & 149.682 & $<.001$ & .100 \\
\hline Cave & 1 & 398.866 & $<.001$ & .228 \\
\hline Sulfide & 1 & 100.839 & $<.001$ & .070 \\
\hline Sex $\times$ cave & 1 & .660 & .417 & $<.001$ \\
\hline Sex $\times$ sulfide & 1 & 1.632 & .202 & .001 \\
\hline Cave $\times$ sulfide & 1 & 292.731 & $<.001$ & .178 \\
\hline \multicolumn{5}{|c|}{$\begin{array}{l}\text { B. Routine metabolic rate of wild-caught fish } \\
\text { ( } \log _{10} \text { transformed): }\end{array}$} \\
\hline Sex & 1 & .001 & .971 & $<.001$ \\
\hline Cave & 1 & 9.458 & .003 & .122 \\
\hline Sulfide & 1 & 3.322 & .073 & .047 \\
\hline $\log ($ mass $)$ & 1 & 210.822 & $<.001$ & .756 \\
\hline Temperature & 1 & .884 & .351 & .013 \\
\hline \multicolumn{5}{|c|}{$\begin{array}{l}\text { C. Routine metabolic rate of laboratory-reared fish } \\
\left(\log _{10} \text { transformed): }\right.\end{array}$} \\
\hline Sex & 1 & .019 & .889 & $<.001$ \\
\hline Food & 1 & 31.87 & $<.001$ & .137 \\
\hline Cave & 1 & 7.616 & .006 & .037 \\
\hline Sulfide & 1 & .294 & .589 & .001 \\
\hline Log(mass) & 1 & 76.603 & $<.001$ & .277 \\
\hline Temperature & 1 & 265.84 & $<.001$ & .571 \\
\hline Food $\times$ cave & 1 & 1.484 & .225 & .007 \\
\hline Food $\times \log ($ mass $)$ & 1 & 10.438 & .001 & .05 \\
\hline Food $\times$ sex & 1 & 3.859 & .051 & .019 \\
\hline Food $\times$ sulfide & 1 & 3.34 & .069 & .016 \\
\hline Cave $\times \log ($ mass $)$ & 1 & 1.315 & .253 & .007 \\
\hline Cave $\times$ sex & 1 & .575 & .449 & .003 \\
\hline Cave $\times$ sulfide & 1 & .007 & .933 & $<.001$ \\
\hline Sex $\times \log ($ mass $)$ & 1 & .257 & .613 & .001 \\
\hline Sulfide $\times \log ($ mass $)$ & 1 & .161 & .689 & .001 \\
\hline Sulfide $\times$ sex & 1 & .082 & .775 & $<.001$ \\
\hline
\end{tabular}

Note. Part A shows comparison of size distributions of fish residing in different habitat types, part B shows comparison of routine metabolic rates in wild-caught individuals, and part $\mathrm{C}$ shows comparison of routine metabolic rates in common garden-raised individuals subjected to different resource availability treatments. Note that the effect size for each of the terms in a model was estimated by use of partial eta squared $\left(\eta_{\mathrm{p}}^{2}\right)$. 

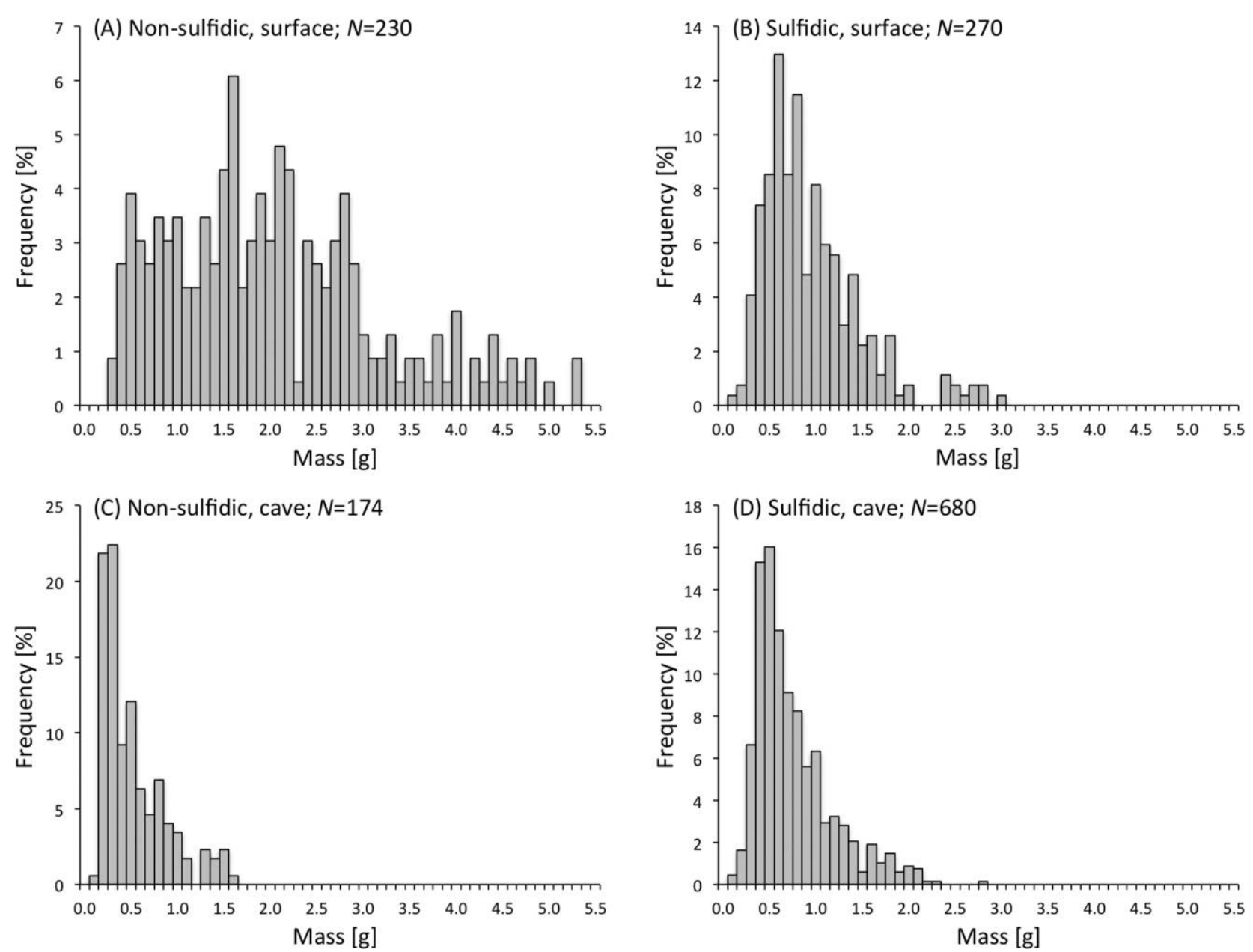

Figure 1. Frequency distributions based on body mass in natural populations. $A$, Arroyo Bonita; $B$, El Azufre; $C$, Cueva Luna Azufre; $D$, Cueva del Azufre. Frequencies are expressed as the percentage of individuals within a size class in each population.

the populations inhabiting extreme environments, sulfidic surface fish were the largest $(0.92 \pm 0.53 \mathrm{~g})$, sulfidic cave individuals were intermediate $(0.75 \pm 0.48 \mathrm{~g})$, and fish from the nonsulfidic cave were the smallest $(0.48 \pm 0.34 \mathrm{~g})$.

\section{Routine Metabolic Rate Variation in Natural Populations}

Analysis of the wild-caught fish revealed significant variation in routine metabolic rates among locally adapted populations. Body mass, as expected, explained most variation in routine metabolism (table 2, pt. B). While there was no difference between sulfidic and nonsulfidic populations, cave fish exhibited significantly higher routine metabolic rates than surface fish (fig. 2A). Temperature did not significantly affect metabolic rates in wild-caught fish, likely because the temperature range was relatively narrow $\left(26^{\circ}-27^{\circ} \mathrm{C}\right)$.

Routine Metabolic Rates and Metabolic Rate Plasticity in Common Garden-Raised Fish

Temperature and mass explained the bulk of variation in routine metabolic rates of laboratory-reared individuals (table 2, pt. C; fig. A1; figs. A1-A3 are available online). Furthermore, laboratory experiments confirmed the significantly higher routine metabolic rates in cave populations (fig. $2 B$ ), as documented in wild-caught fish. Similarly, there was no significant difference between fish from sulfidic and nonsulfidic habitats. In addition, fish receiving the high food treatment exhibited higher routine metabolic rates than those receiving low food treatments, although these differences were dependent on body mass (see the significant food $\times$ mass interaction term in table 2 , pt. C). Specifically, reductions in routine metabolic rates were more pronounced in larger individuals than in smaller ones (fig. 3). Finally, there was no evidence for population differences in response to food treatments or in the temperature dependence of metabolic rates.

\section{Discussion}

Our study revealed significant variation in traits associated with energy metabolism among locally adapted populations of Poecilia mexicana inhabiting contrasting environments characterized by the presence or absence of light and toxic hydrogen sulfide. In particular, we found significant reductions in 
body size in extremophile populations and significant amongpopulation variation in routine metabolic rates of wild-caught individuals, although analyses of body size variation and metabolic rates yielded somewhat contradictory results. Laboratory experiments using common garden-raised fish revealed genetic variation in routine metabolic rates, likely indicating evolved differences in energy metabolism among populations of the same species.

\section{Reducing Organismal Energy Demands: \\ Patterns and Mechanisms}

Reduced resource availability and increased maintenance costs often associated with extreme environments are predicted to exert selection for reduced energy demands, allowing organisms adapted to the extreme conditions to maximize the relative investment into reproduction (Brown et al. 1993; Parsons 1996). Our analyses indicated significant reductions in body mass for all populations from habitats with extreme environmental conditions, supporting the notion that selection acts to reduce organismal energy demands. Contrary to predictions, however, cave fish exhibited significantly higher routine metabolic rates than fish from surface populations (irrespective of the presence of $\mathrm{H}_{2} \mathrm{~S}$ in natural waters). These contradictory results beg the question of whether variation in body size and metabolic rate balance each other in a way that overall organismal energy demands do not vary among populations living under different environmental conditions or whether reductions in body mass outweigh increases in routine metabolic rates. Simulating total energy expenditure of average individuals from the different populations under simultaneous consideration of population-specific size distributions and allometric metabolic rate functions (see the appendix, available online, for details) indicated that body mass reductions outweigh differences in routine metabolic rate. In fact, estimates of total energy expenditure were significantly and substantially reduced (between $27 \%$ and $49 \%$ ) in fish from extreme habitats compared with that in the ancestral nonsulfidic surface population (fig. A2), which provides unequivocal evidence for a reduction in energy demands in extreme environments. Hence, the reduction in body size outweighed the increase in metabolic rates, highlighting that variation in body size and metabolic rates need to be considered simultaneously because investigating one without the other may lead to spurious conclusions (e.g., McNab 1999).

Reductions in energy demands in extremophile populations were primarily driven by modification of body size rather than metabolic rate suppression. This parallels results from selection experiments, in which mice selected for high locomotor activity maintained stable energy budgets despite high costs because they exhibited reductions in body size rather than reductions in mass-specific costs associated with running (Rezende et al. 2009). Consequently, modification of body size may face fewer evolutionary constraints than modification of metabolic rates, which would explain the tight correlation between mass and metabolic rate across a broad range of taxa (Gillooly et al.

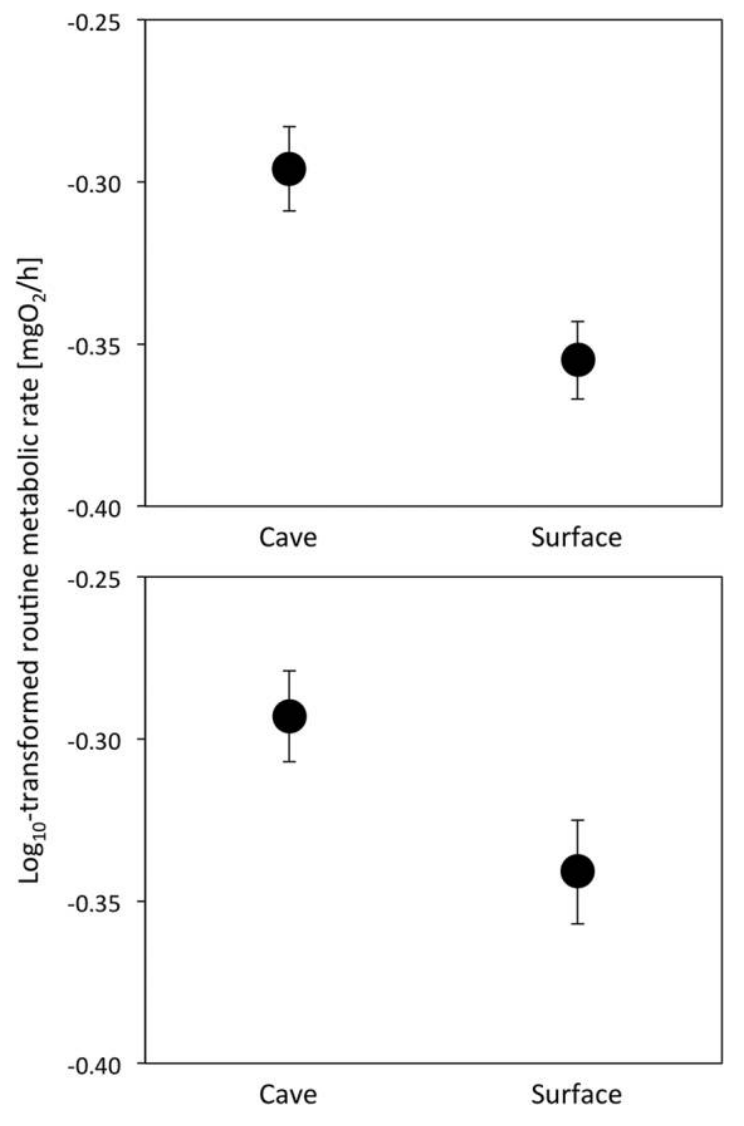

Figure 2. A, Differences in routine metabolic rates between cave and surface populations for wild-caught individuals. Depicted are estimated marginal means $( \pm S D)$ of routine metabolic rates derived from the analytical model in table 2, part B. Mean values of covariates used for the calculation of estimated marginal means were as follows: mass $\left(\log _{10}\right.$ transformed $)=-0.134 \mathrm{~g}$, temperature $=26.7^{\circ} \mathrm{C} . B$, Differences in routine metabolic rates between cave and surface populations for laboratory-reared individuals. Depicted are estimated marginal means $( \pm S D$ ) of routine metabolic rates derived from the analytical model in table 2, part C. Mean values of covariates used for the calculation of estimated marginal means were as follows: mass $\left(\log _{10}\right.$ transformed $)=-0.125 \mathrm{~g}$, temperature $=25.9^{\circ} \mathrm{C}$.

2001; Brown et al. 2004). While common-garden experiments revealed a genetic component to variation in routine metabolic rates (cave fish retained elevated routine metabolic rates when raised in the laboratory for multiple generations), it remains unclear whether variation in body size among populations living in contrasting environments is driven by genetically based evolutionary change or phenotypic plasticity. Particularly in fishes that have indeterminate growth, there is substantial evidence for both heritable and plastic components underlying variation in body size (e.g., Campton 1992; Hughes et al. 2005; Hard et al. 2008). Overall, our study provides strong evidence that living in and adapting to extreme environments is linked to modification of energy metabolism, even though proximate mechanisms remain to be studied and ultimate mechanisms may differ between sulfidic and cave habitats. 


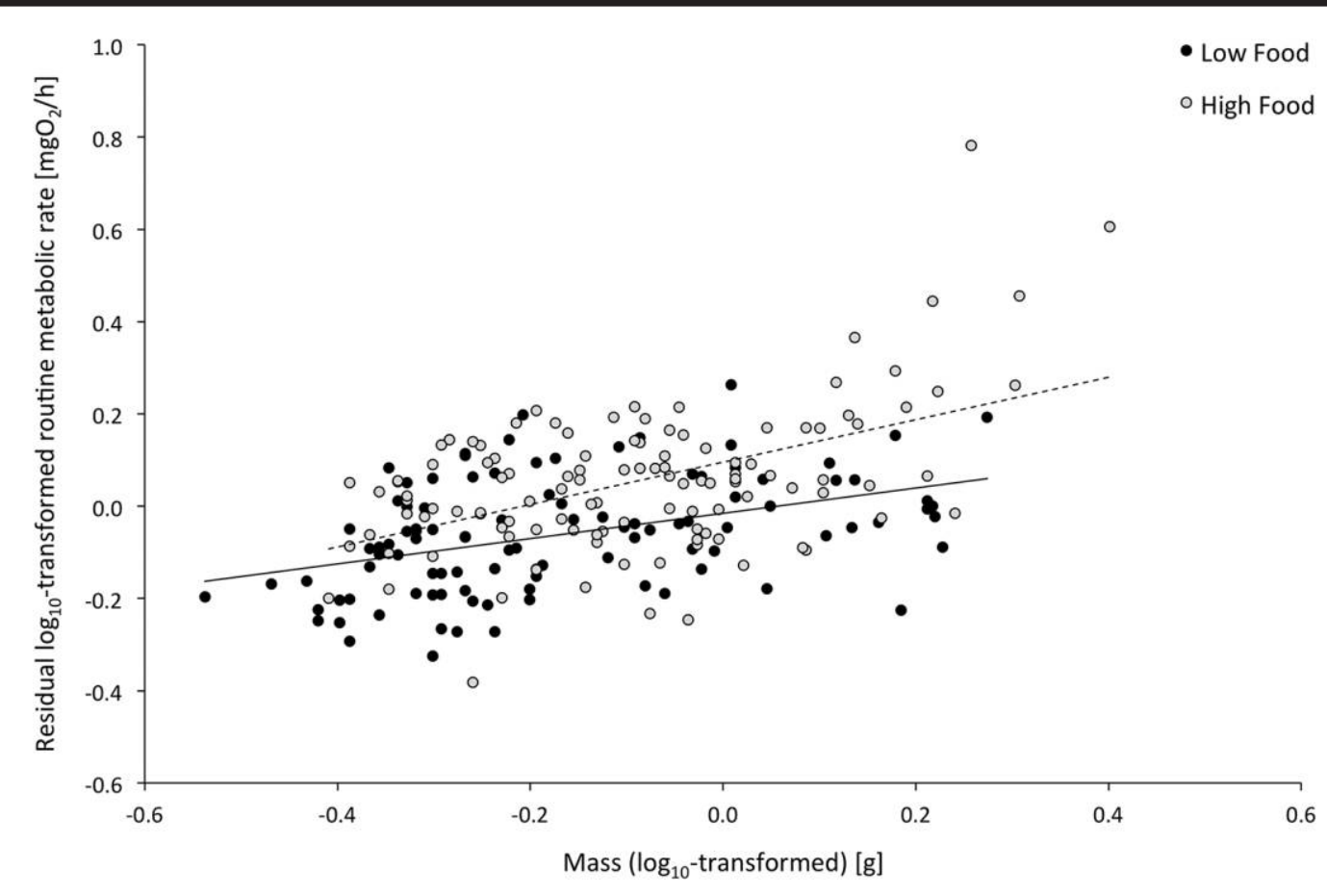

Figure 3. Relationship between body mass and routine metabolic rates for laboratory-raised fish receiving the high and low food treatments. Depicted are residuals from the analytical model (without mass and food treatment) presented in table 2, part C.

\section{Metabolic Rate Variation in Cave Environments}

Caves are typically considered to have low resource availability due to the lack of photosynthetic primary production (Poulson and White 1969; Langecker 2000). Accordingly, a diversity of cave organisms have been reported to exhibit reduced metabolic rates compared with close relatives from surface habitats (see Hüppop 1985 for a review). To our knowledge, no previous studies have investigated to what degree body size reduction and metabolic rate suppression have contributed to decreases in energetic demands. However, it is important to note that inferences about energy metabolism in other cave organisms have primarily focused on mass-adjusted routine metabolic rates (e.g., Poulson 1963; Culver and Poulson 1971; Hüppop 1985; Hervant et al. 1997; Hervant et al. 2001), and - at least in some cases - there is evidence for selection for increased body size in cave populations (Culver et al. 1995; Christiansen 2012), presumably to increase starvation resistance in temperate caves with temporal periodicity of food (Hüppop 2000). Contrary to other cave organisms, our data indicate that cavernicolous individuals of $P$. mexicana have higher routine metabolic rates than relatives from surface habitats, such that overall reductions in energetic demands are primarily driven by reductions in body size. This discrepancy may be explained by the fact that resource availability in many tropical caves is comparatively stable over time due to reduced seasonality (Hüppop 2000). Hence, cave populations of $P$. mexicana may have adapted to perpetual rather than temporal shortages of energy. In the cave habitats inves- tigated here, continuous supply of food is mediated by bat colonies depositing guano (in both caves) and by chemoautotrophic primary production by sulfide-oxidizing bacteria (in the sulfidic cave; Roach et al. 2011). Interestingly, fish from the nonsulfidic cave lacking any sort of primary production exhibited a more pronounced reduction of simulated total energy expenditure than fish from the sulfidic cave; hence, overall energy availability is likely a key determinant of metabolic rate evolution in this system.

Cave fish having higher routine metabolism than their surface counterparts also poses the question of whether increased energy consumption was caused by behavioral differences. Poeciliids generally are diurnal (Coleman 2011). The darkness of the respirometry chambers could have reduced activity levels of surface fish, while cave fish remained active and maintained elevated routine metabolic rates. Indeed, cave populations of $P$. mexicana are characterized by sensory and behavioral adaptations to permanent darkness, which are absent in surface ancestors (Parzefall 2001; Plath et al. 2004; Rüschenbaum and Schlupp 2013). However, quantifying activity of fish in complete darkness indicated that cave fish did not have consistently higher activity than surface fish. Instead, fish from extreme habitats generally had a higher activity than those from the ancestral nonsulfidic surface population, and sex differences were idiosyncratic across all populations investigated (significant three-way interaction term including presence of light, presence of $\mathrm{H}_{2} \mathrm{~S}$, and sex; see the appendix for details). Nonetheless, future studies should more rigorously test how individual variation in behavior affects met- 
abolic rates and vice versa (see Biro and Stamps 2010; Careau and Garland 2012).

\section{Metabolic Rate Variation in Sulfidic Environments}

Similar to fish in caves, fish in sulfidic habitats exhibited a body size-driven reduction in simulated total energy expenditure (appendix; fig. A2). In contrast, we did not find differences in routine metabolic rates between sulfidic and nonsulfidic populations (irrespective of whether they were located in cave or surface habitats). This contradicted previous hypotheses that predicted either lower metabolic rates (in response to energy shortage or the rampant hypoxia in sulfidic environments) or higher metabolic rate in sulfidic fish (in response to increased metabolic costs of sulfide detoxification; Riesch et al. 2011b). It is important to note, however, that it remains unclear how routine metabolic rates measured in our experimental setup compare with routine metabolic rates in situ because all oxygen consumption measurements were conducted in the absence of $\mathrm{H}_{2} \mathrm{~S}$. In general, the presence of physiochemical stressors and toxicants can increase metabolic rates because coping strategies and detoxification pathways are energetically costly (Penttinen and Kukkonen 1998; Rose et al. 2006; McKenzie et al. 2007). In metazoans, $\mathrm{H}_{2} \mathrm{~S}$ detoxification is primarily linked to the sulfide:quinone oxidoreductase pathway (Griesbeck et al. 2000; Shahak and Hauska 2008), which oxidizes sulfide to less-toxic forms of sulfur while consuming energy (Ip et al. 2004; Hildebrandt and Grieshaber 2008). Poecilia from sulfidic habitats have consistently upregulated genes associated with $\mathrm{H}_{2} \mathrm{~S}$ detoxification both in natural habitats (J. L. Kelley, C. N. Passow, L. AriasRodriguez, D. P. Martin, M.-C. Yee, C. D. Bustamante, and M. Tobler, unpublished data) and on experimental sulfide exposure in the laboratory (Tobler et al. 2014). However, it remains to be tested whether exposure to $\mathrm{H}_{2} \mathrm{~S}$ increases metabolic rates in $P$. mexicana in a similar fashion as in some sulfide-adapted invertebrates (Gorodezky and Childress 1994; Schneider 1996), in which case the present study would have overestimated differences in overall energy consumption between sulfidic and nonsulfidic populations. Because $\mathrm{H}_{2} \mathrm{~S}$ also blocks cytochrome $\mathrm{c}$ oxidase $(\mathrm{COX})$ in the mitochondrial respiratory chain (Cooper and Brown 2008), sulfide exposure can also cause metabolic rate depression (Brauner et al. 1995; Blackstone et al. 2005; Volpato et al. 2008), and this may be particularly relevant for the populations investigated here. Unlike other evolutionarily lineages of sulfide spring Poecilia in southern Mexico that have evolved $\mathrm{H}_{2} \mathrm{~S}$-resistant COXs, sulfide spring populations in the Tacotalpa drainage used in the present study exhibit an $\mathrm{H}_{2} \mathrm{~S}$-susceptible $\mathrm{COX}$ similar to that found in ancestral nonsulfidic populations (Pfenninger et al. 2014). Consequently, there is also a possibility that our study actually underestimated differences in energy consumption between sulfidic and nonsulfidic populations in their natural habitats, and future experiments will need to isolate the potential effects of $\mathrm{H}_{2} \mathrm{~S}$ exposure in driving metabolic rate variation in natural populations.

\section{Conclusions}

Variation in metabolic rates is central to several physiological and ecological theories (e.g., Kooijman 2000; Brown et al. 2004), but we know comparatively little about the microevolutionary mechanisms that drive macroevolutionary patterns of metabolic rate variation. Our study indicates that adaptation to extreme environmental conditions is manifested in changes in energy metabolism (Parsons 1996), leading to striking intraspecific variation in energetic demands at small spatial scales. Notably, extremophiles have consistent reductions in body size in natural habitats that drive an overall reduction of energy demands. Hence, environmentally induced changes in energy supply and demand may be a major diving force in metabolic rate evolution (Mueller and Diamond 2001).

\section{Acknowledgments}

We are indebted to the staff at the Centro de Investigación e Innovación para la Enseñanza y el Aprendizaje in Teapa, Tabasco, for their logistical support and hospitality. We thank D. Alba, T. Doumas, and R. Morehouse for help in the field; I. Schlupp for providing laboratory-reared fish; M. Lovern for lending us a video camera; and the Mexican government for issuing permits (DGOPA.09004.041111.3088). Financial support was provided by an American Livebearer Association Vern Parish Award (to C.N.P.), a Wentz and a Niblack Scholarship (to R.G.), and an Oak Ridge Associated Universities Ralph E. Powe Junior Faculty Enhancement Award and National Science Foundation grant IOS-1121832 (to M.T.).

\section{Literature Cited}

Allen B.J. and J.S. Levinton. 2007. Costs of bearing a sexually selected ornamental weapon in a fiddler crab. Funct Ecol 21:154-161.

Bagarinao T. 1992. Sulfide as an environmental factor and toxicant: tolerance and adaptations in aquatic organisms. Aquat Toxicol 24:21-62.

Basolo A.L. and G. Alcaraz. 2003. The turn of the sword: length increases male swimming costs in swordtails. Proc $\mathrm{R}$ Soc B 270:1631-1636.

Biro P.A. and J.A. Stamps. 2010. Do consistent individual differences in metabolic rate promote consistent individual differences in behavior? Trends Ecol Evol 25:653-659.

Blackstone E., M. Morrison, and M.B. Roth. 2005. $\mathrm{H}_{2} \mathrm{~S}$ induces a suspended animation-like state in mice. Science 308:518.

Blanckenhorn W.U. 2000. The evolution of body size: what keeps organisms small? Q Rev Biol 75:385-407.

Brauner C.J., C.L. Ballantyne, D.J. Randall, and A.L. Val. 1995. Air-breathing in the armored catfish (Hoplosternum littorale) as an adaptation to hypoxic, acidic, and hydrogen sulfide-rich waters. Can I Zool 73:739-744.

Brown J.H., J.F. Gillooly, A.P. Allen, V.M. Savage, and G.B. West. 2004. Towards a metabolic theory of ecology. Ecology 85:1771-1789. 
Brown J.H., P.A. Marquet, and M.L. Taper. 1993. Evolution of body size: consequences of an energetic definition of fitness. Am Nat 142:573-584.

Burton T., S.S. Killen, J.D. Armstrong, and N.B. Metcalfe. 2011. What causes intraspecific variation in resting metabolic rate and what are its ecological consequences? Proc R Soc B 278:3465-3473.

Calow P. 1989. Proximate and ultimate responses to stress in biological systems. Biol J Linn Soc 37:173-181.

Campton D.E. 1992. Heritability of body size of green swordtails, Xiphophorus helleri. I. Sib analyses of males reared individually and in groups. J Hered 83:43-48.

Cano J.M. and A.G. Nicieza. 2006. Temperature, metabolic rate, and constraints on locomotor performance in ectotherm vertebrates. Funct Ecol 20:464-470.

Careau V. and T. Garland Jr. 2012. Performance, personality, and energetics: correlation, causation, and mechanism. Phvsiol Biochem Zool 85:543-571.

Chen K.Y. and J.C. Morris. 1972. Kinetics of oxidation of aqueous sulfide by $\mathrm{O}_{2}$. Environ Sci Technol 6:529-537.

Cho C.Y., S.J. Slinger, and H.S. Bayley. 1982. Bioenergetics of salmonid fishes: energy intake, expenditure and productivity. Comp Biochem Physiol B 73:25-41.

Christiansen K. 2012. Morphological adaptations. Pp. 517528 in D.C. Culver and W.B. White, eds. Encyclopedia of caves. 2nd ed. Elsevier, Amsterdam.

Clarke A. and K.P.P. Fraser. 2004. Why does metabolism scale with temperature? Funct Ecol 18:243-251.

Clarke A. and N.M. Johnston. 1999. Scaling of metabolic rate with body mass and temperature in teleost fish. LAnim Ecol 68:893-905.

Coleman S.W. 2011. Sensory ecology. Pp. 72-81 in J. Evans, A. Pilastro, and I. Schlupp, eds. Ecology and evolution of poeciliid fishes. University of Chicago Press, Chicago.

Constantz G.D. 1989. Reproductive biology of poeciliid fishes. Pp. 33-50 in G.K. Meffe and F.F. Snelson, eds. Ecology and evolution of livebearing fishes (Poeciliidae). Prentice Hall, Upper Saddle River, NJ.

Cooper C.E. and G.C. Brown. 2008. The inhibition of mitochondrial cytochrome oxidase by the gases carbon monoxide, nitric oxide, hydrogen cyanide and hydrogen sulfide: chemical mechanism and physiological significance. I Bioenergy Biomembr 40:533-539.

Culver D.C., T.C. Kane, and D.W. Fong. 1995. Adaptation and natural selection in caves. Harvard University Press, Cambridge, MA.

Culver D.C. and T.L. Poulson. 1971. Oxygen consumption and activity in closely related amphipod populations from cave and surface habitats. Am Midl Nat 85:74-84.

Feder M.E., A.F. Bennett, and R.B. Huey. 2000. Evolutionary physiology. Annu Rev Ecol Syst 31:315-341.

Fry F.E.J. 1957. The aquatic respiration of fish. Pp. 1-63 in M.E. Brown, ed. The physiology of fishes. Academic Press, New York.

Garland T. and P.A. Carter. 1994. Evolutionary physiology. Annu Rev Physiol 56:579-621.
Gillooly J.F., J.H. Brown, G.B. West, V.M. Savage, and E.L. Charnov. 2001. Effects of size and temperature on metabolic rates. Science 239:2248-2251.

Gordon M.S. and D.E. Rosen. 1962. A cavernicolous form of the poeciliid fish Poecilia sphenops from Tabasco, México. Copeia 1962:360-368.

Gorodezky L.A. and J.J. Childress. 1994. Effects of sulfide exposure history and hemolymph thiosulfate on oxygenconsumption rates and regulation in the hydrothermal vent crab Bythograea thermydron. Marine Biology 120:123-131.

Griesbeck C., G. Hauska, and M. Schutz. 2000. Biological sulfide oxidation: sulfide-quinone reductase (SQR), the primary reaction. Pp. 179-203 in S.G. Pandalai, ed. Recent research developments in microbiology. Research Signpost, Trivandrum, India.

Guppy M. and P. Withers. 1999. Metabolic depression in animals: physiological perspectives and biochemical generalizations. Biol Rev 74:1-40.

Haney D.C. and F.G. Nordlie. 1997. Influence of environmental salinity on routine metabolic rate and critical oxygen tension of Cyprinodon variegatus. Physiol Zool 70:511-518.

Hard J.J., M.R. Gross, M. Heino, R. Hilborn, R.G. Kope, R. Law, and J.D. Reynolds. 2008. Evolutionary consequences of fishing and their implications for salmon. Evol Appl 1: 388-408.

Hervant F., J. Mathieu, H. Barré, K. Simon, and C. Pinon. 1997. Comparative study on the behavioral, ventilatory, and respiratory responses of hypogean and epigean crustaceans to long-term starvation and subsequent feeding. Comp Biochem Physiol A 118:1277-1283.

Hervant F., J. Mathieu, and J.P. Durand. 2000. Metabolism and circadian rhythms of the European blind cave salamander Proteus anguinus and a facultative cave dweller, the Pyrenean newt (Euproctus asper). Can I Zool 78:1427-1432.

Hervant F., J. Mathieu, and J. Durant. 2001. Behavioural, physiological and metabolic responses to long-term starvation and refeeding in a blind cave-dwelling (Proteus anguinus) and surface-dwelling (Euproctus asper) salamander. LExp Biol 204:269-281.

Hildebrandt T.M. and M. Grieshaber. 2008. Three enzymatic activities catalyze the oxidation of sulfide to thiosulfate in mammalian and invertebrate mitochondria. FEBS I 275: 3352-3361.

Hoback W.W. and W.E. Wagner. 1997. The energetic cost of calling in the variable field cricket, Gryllus lineaticeps. Physiol Entomol 22:286-290.

Hughes K.A., F.H. Rodd, and D. Reznick. 2005. Genetic and environmental effects on secondary sex traits in guppies (Poecilia reticulata). L Evol Biol 18:35-45.

Hüppop K. 1985. The role of metabolism in the evolution of cave animals. Bull Nat Speleol Soc 47:136-146.

- 1986. Oxygen consumption of Astyanax fasciatus (Characidae, Pisces): a comparison of epigean and hypogean populations. Environ Biol Fishes 17:299-308.

. 2000. How do cave animals cope with the food scarcity in caves? Pp. 159-188 in H. Wilkens, D.C. Culver, and 
W.F. Humphreys, eds. Ecosystems of the world 30: subterranean ecosystems. Elsevier Science, Amsterdam.

Ip Y.K., S.S.L. Kuah, and S.F. Chew. 2004. Strategies adopted by the mudskipper Boleophthalmus boddaerti to survive sulfide exposure in normoxia or hypoxia. Physiol Biochem Zool 77:824-837.

Knoblauch C., B.B. Jorgensen, and J. Harder. 1999. Community size and metabolic rates of psychrophilic sulfatereducing bacteria in arctic marine sediments. Appl Environ Microbiol 65:4230-4233.

Kooijman S.A.L.M. 2000. Dynamic energy and mass budgets in biological systems. Cambridge University Press, Cambridge.

Langecker T.G. 2000. The effect of continuous darkness on cave ecology and cavernicolous evolution. Pp. 135-157 in H. Wilkens, D.C. Culver, and W.F. Humphreys, eds. Ecosystems of the world 30: subterranean ecosystems. Elsevier Science, Amsterdam.

Lovegrove B.G. 2000. The zoogeography of mammalian basal metabolic rate. Am Nat 156:201-219.

McCue M.D. 2010. Starvation physiology: reviewing the different strategies animals use to survive a common challenge. Comp Biochem Physiol A 156:1-18.

McKenzie D.J., E. Garofalo, M.J. Winter, S. Ceradini, F. Verweij, N. Day, R. Hayes, et al. 2007. Complex physiological traits as biomarkers of the sub-lethal toxicological effects of pollutant exposure in fishes. Philos Trans R Soc Lond B Biol Sci 362:2043-2059.

McNab B.K. 1986. The influence of food habits on the energetics of eutherian mammals. Ecol Monogr 56:1-19.

- 1999. On the comparative ecological and evolutionary significance of total and mass-specific rates of metabolism. Physiol Biochem Zool 72:642-644.

2002. The physiological ecology of vertebrates: a view from energetics. Cornstock, Ithaca, NY.

- 2010. Geographic and temporal correlations of mammalian size reconsidered: a resource rule. Oecologia 164: 13-23.

Moiroux J., D. Giron, P. Vernon, J. van Baaren, and J.J.M. van Alphen. 2012. Evolution of metabolic rate in a parasitic wasp: the role of limitation in intrinsic resources. I Insect Phvsiol 58:979-984.

Mueller P. and J. Diamond. 2001. Metabolic rate and environmental productivity: well-provisioned animals evolved to run and idle fast. Proc Natl Acad Sci USA 98:1255012554.

Nagy K.A., I.A. Girard, and T.K. Brown. 1999. Energetics of free-ranging mammals, reptiles, and birds. Annu Rev Nutr 19:247-277.

Naya D.E., L. Spangenberg, H. Naya, and F. Bozinovic. 2013. How does evolutionary variation in basal metabolic rates arise? a statistical assessment and a mechanistic model. Evolution 67:1463-1476.

Norin T. and H. Malte. 2011. Repeatability of standard metabolic rate, active metabolic rate, and aerobic scope in young brown trout during a period of moderate food availability. LExp Biol 214:1668-1675.
Pafilis P., S. Meiri, J. Foufopoulos, and E. Valakos. 2009. Intraspecific competition and high food availability are associated with insular gigantism in a lizard. Naturwissenschaften 96:1107-1113.

Parsons P.A. 1996. Stress, resources, energy balances, and evolutionary change. Pp. 39-72. Evolutionary biology. Vol. 29. Plenum, New York.

Parzefall J. 2001. A review of morphological and behavioural changes in the cave molly, Poecilia mexicana, from Tabasco, Mexico. Environ Biol Fishes 62:263-275.

Penttinen O.P. and J. Kukkonen. 1998. Chemical stress and metabolic rate in aquatic invertebrates: threshold, doseresponse relationships, and mode of toxic action. Environ Toxicol Chem 17:883-890.

Peters R.H. 1983. The ecological implications of body size. Cambridge University Press, Cambridge.

Pfenninger M., H. Lerp, M. Tobler, C. Passow, J.L. Kelley, E. Funke, B. Greshake, U.K. Erkoc, T. Berberich, and M. Plath. 2014. Parallel evolution of cox genes in $\mathrm{H}_{2} \mathrm{~S}$-tolerant fish as key adaptation to a toxic environment. Nature Comm 5:3873.

Pirozzi I. and M.A. Booth. 2009. The routine metabolic rate of mulloway (Argurosomus japonicus: Sciaenidae) and yellowtail kingfish (Seriola lalandi: Carangidae) acclimated to six different temperatures. Comp Biochem Physiol A 152:586-592.

Plath M., S. Hauswaldt, K. Moll, M. Tobler, F. Garcia de Leon, I. Schlupp, and R. Tiedemann. 2007a. Local adaptation and pronounced genetic differentiation in an extremophile fish, Poecilia mexicana, inhabiting a Mexican cave with toxic hydrogen sulfide. Mol Ecol 16:967-976.

Plath M., C. Hermann, R. Schröder, R. Riesch, M. Tobler, F.J. Garcia de Leon, I. Schlupp, and R. Tiedemann. 2010. Locally adapted fish populations maintain small-scale genetic differentiation despite perturbation by a catastrophic flood event. BMC Evol Biol 10:256.

Plath M., K.U. Heubel, F.J. Garcia de Leon, and I. Schlupp. 2005. Cave molly females (Poecilia mexicana, Poeciliidae, Teleostei) like well-fed males. Behav Ecol Sociobiol 58:144-151.

Plath M., J. Parzefall, K. Körner, and I. Schlupp. 2004. Sexual selection in darkness? female mating preferences in surface- and cave-dwelling Atlantic mollies, Poecilia mexicana (Poeciliidae, Teleostei). Behav Ecol Sociobiol 55:596-601.

Plath M. and M. Tobler. 2010. Subterranean fishes of Mexico (Poecilia mexicana, Poeciliidae). Pp. 283-332 in E. Trajano, M.E. Bichuette, and B.G. Kapoor, eds. The biology of subterranean fishes. Science, Enfield, NH.

Plath M., M. Tobler, R. Riesch, F.J. Garcia de Leon, O. Giere, and I. Schlupp. 2007b. Survival in an extreme habitat: the role of behaviour and energy limitation. Naturwissenschaften 94:991-996.

Poulson T.L. 1963. Cave adaptation in amblyopsid fishes. Am Midl Nat 70:257-290.

. 2001. Morphological and physiological correlates of evolutionary reduction of metabolic rate among amblyopsid cave fishes. Environ Biol Fishes 62:239-249.

Poulson T.L. and W.B. White. 1969. The cave environment. Science 165:971-981. 
Rezende E.L., F.R. Gomes, M.A. Chappell, and T. Garland Jr. 2009. Running behavior and its energy cost in mice selectively bred for high voluntary locomotor activity. Physiol Biochem Zool 82:662-679.

Reznick D. and D.B. Miles. 1989. Review of life history patterns in poeciliid fishes. Pp. 125-148 in G.K. Meffe and F.F. Snelson, eds. Ecology and evolution of lifebearing fishes (Poeciliidae). Prentice Hall, Upper Saddle River, NJ.

Riesch R., M. Plath, and I. Schlupp. 2011a. Speciation in caves: experimental evidence that permanent darkness promotes reproductive isolation. Biology Letters 7:909-912.

Riesch R., I. Schlupp, E. Schleucher, P. Hildenbrand, A. Kohler, L. Arias-Rodriguez, and M. Plath. 2011b. Reduced starvation resistance and increased metabolic rates in an unusual cave organism: the cave molly (Poecilia mexicana). Bull Fish Biol 13:41-56.

Roach K., M. Tobler, and K.O. Winemiller. 2011. Hydrogen sulfide, bacteria, and fish: a unique, subterranean food chain. Ecology 92:2056-2062.

Rose W.L., R.M. Nisbet, P.G. Green, S. Norris, T. Fan, E.H. Smith, G.N. Cherr, and S.L. Anderson. 2006. Using an integrated approach to link biomarker responses and physiological stress to growth impairment of cadmium-exposed larval topsmelt. Aquat Toxicol 80:298-308.

Rüschenbaum S. and I. Schlupp. 2013. Non-visual mate choice ability in a cavefish (Poecilia mexicana) is not mechanosensory. Ethology 119:368-376.

Schaefer J. and A. Walters. 2010. Metabolic cold adaptation and developmental plasticity in metabolic rates among species in the Fundulus notatus species complex. Funct Ecol 24:1087-1094.

Schneider A. 1996. Metabolic rate of the brackish water polychaete Marenzelleria viridis under reducing conditions. Thermochim Acta 271:31-40.

Seibel B.A. and J.C. Drazen. 2007. The rate of metabolism in marine animals: environmental constraints, ecological demands and energetic opportunities. Philos Trans R Soc Lond B Biol Sci 362:2061-2078.

Shahak Y. and G. Hauska. 2008. Sulfide oxidation from cyanobacteria to humans: sulfide-quinone oxidoreductase (SQR). Pp. 319-335 in R. Hell, C. Dahl, D.B. Knaff, and L. T, eds. Advances in photosynthesis and respiration. Springer, Heidelberg.

Sibly R.M., J.H. Brown, and A. Kodric-Brown, eds. 2012. Metabolic ecology: a scaling approach. Wiley-Blackwell, Oxford.

Sibly R.M. and P. Calow. 1989. A life-cycle theory of responses to stress. Biol I Linn Soc 37:101-116.

Steffensen J.F. 1989. Some errors in respirometry of aquatic breathers: how to avoid and correct for them. Fish Physiol Biochem 6:49-59.

Timmerman C.M. and L.J. Chapman. 2003. The effect of gestational state on oxygen consumption and response to hypoxia in the sailfin molly, Poecilia latipinna. Environ Biol Fishes 68:293-299.

. 2004a. Behavioral and physiological compensation for chronic hypoxia in the sailfin molly (Poecilia latipinna). Physiol Biochem Zool 77:601-610. 2004b. Hypoxia and interdemic variation in Poecilia latipinna. L Fish Biol 65:635-650.

Tobler M. 2008. Divergence in trophic ecology characterizes colonization of extreme habitats. Biol I Linn Soc 95:517528.

. 2009. Does a predatory insect contribute to the divergence between cave- and surface-adapted fish populations? Biol Lett 5:506-509.

Tobler M., T.J. DeWitt, I. Schlupp, F.J. Garcia de Leon, R. Herrmann, P. Feulner, R. Tiedemann, and M. Plath. 2008a. Toxic hydrogen sulfide and dark caves: phenotypic and genetic divergence across two abiotic environmental gradients in Poecilia mexicana. Evolution 62:2643-2649.

Tobler M., C. Henpita, B. Bassett, J.L. Kelley, and J. Shaw. 2014. $\mathrm{H}_{2} \mathrm{~S}$ exposure elicits differential expression of candidate genes in fish adapted to sulfidic and non-sulfidic environments. Comp Biochem Physiol A 175:7-14.

Tobler M., M. Palacios, L.J. Chapman, I. Mitrofanov, D. Bierbach, M. Plath, L. Arias-Rodriguez, F.J. Garcia de Leon, and M. Mateos. 2011. Evolution in extreme environments: replicated phenotypic differentiation in livebearing fish inhabiting sulfidic springs. Evolution 65:2213-2228.

Tobler M. and M. Plath. 2011. Living in extreme habitats. Pp. 120-127 in J. Evans, A. Pilastro, and I. Schlupp, eds. Ecology and evolution of poeciliid fishes. University of Chicago Press, Chicago.

Tobler M., R. Riesch, F.J. Garcia de Leon, I. Schlupp, and M. Plath. 2008b. A new and morphologically distinct cavernicolous population of Poecilia mexicana (Poeciliidae, Teleostei). Environ Biol Fishes 82:101-108.

Tobler M., R. Riesch, C.M. Tobler, and M. Plath. 2009a. Compensatory behaviour in response to sulfide-induced hypoxia affects time budgets, feeding efficiency, and predation risk. Evol Ecol Res 11:935-948.

Tobler M., R. Riesch, C.M. Tobler, T. Schulz-Mirbach, and M. Plath. 2009b. Natural and sexual selection against immigrants maintains differentiation among micro-allopatric populations. LEvol Biol 22:2298-2304.

Tobler M., I. Schlupp, K. Heubel, R. Riesch, F.J. Garcia de Leon, O. Giere, and M. Plath. 2006. Life on the edge: hydrogen sulfide and the fish communities of a Mexican cave and surrounding waters. Extremophiles 10:577-585.

Tobler M., I. Schlupp, and M. Plath. 2008c. Does divergence in female mate choice affect male size distribution in two cave fish populations? Biol Lett 4:452-454.

Ultsch G.R., H. Boschung, and M.J. Ross. 1978. Metabolism, critical oxygen tension and habitat selection in darters (Etheostoma). Ecology 59:99-107.

Van Voorhies W.A., A.A. Khazaeli, and J.W. Curtsinger. 2004. Lack of correlation between body mass and metabolic rate in Drosophila melanogaster. I Insect Physiol 50:445-453.

Volpato G.P., R. Searles, B. Yu, M. Scherrer-Crosbie, K.D. Bloch, F. Ichinose, and W.M. Zapol. 2008. Inhaled hydrogen sulfide - a rapidly reversible inhibitor of cardiac and metabolic function in the mouse. Anesthesiology 108:659668. 
Wang T., C.C. Hung, and D.J. Randall. 2006. The comparative physiology of food deprivation: from feast to famine. Annu Rev Physiol 68:223-251.

Waterman T.H. 1999. The evolutionary challenges of extreme environments (part 1). LExp Zool 285:326-359.

2001. Evolutionary challenges of extreme environments (part 2). LExp Zool 291:130-168.
Wikelski M. and L.M. Romero. 2003. Body size, performance and fitness in Galapagos marine iguanas. Integr Comp Biol 43:376-386.

Wilhelm F.M., S.J. Taylor, and G.L. Adams. 2006. Comparison of routine metabolic rates of the stygobite, Gammarus acherondytes (Amphipoda: Gammaridae) and the stygophile, Gammarus troglophilus. Freshw Biol 51:1162-1174. 